\title{
Venous Thromboembolism Prophylaxis
}

\author{
Jonathan Laryea, MD, FACS, FASCRS ${ }^{1}$ Bradley Champagne, MD, FACS, FASCRS 2 \\ ${ }^{1}$ Division of Colon and Rectal Surgery, Department of surgery, \\ University of Arkansas for Medical Sciences, Little Rock, Arkansas \\ 2 Division of Colon and Rectal Surgery, Department of surgery, Case \\ Address for correspondence Jonathan Laryea, MD, FACS, FASCRS, \\ University of Arkansas for Medical Sciences, 4301 W Markham St, Slot \\ 520, Little Rock, Arkansas 72205 (e-mail: jalaryea@uams.edu).
} Western Reserve University, Cleveland, Ohio

Clin Colon Rectal Surg 2013;26:153-159.

\begin{abstract}
Keywords

- venous thromboembolism

- deep venous thrombosis

- pulmonary embolism

- prevention

- mechanical agents

- pharmacologic agents

- risk stratification

Venous thromboembolism (VTE) can occur after major general surgery. Pulmonary embolism is recognized as the most common identifiable cause of death in hospitalized patients in the United States. The risk of deep venous thrombosis (DVT) and pulmonary embolism (PE) is higher in colorectal surgical procedures compared with general surgical procedures. The incidence of venous thromboembolism in this population is estimated to be 0.2 to $0.3 \%$. Prevention of VTE is considered a patient-safety measure in most mandated quality initiatives. The measures for prevention of VTE include mechanical methods (graduated compression stockings and intermittent pneumatic compression devices) and pharmacologic agents. A combination of mechanical and pharmacologic methods produces the best results. Patients undergoing surgery should be stratified according to their risk of VTE based on patient risk factors, disease-related risk factors, and procedure-related risk factors. The type of prophylaxis should be commensurate with the risk of VTE based on the composite risk profile.
\end{abstract}

Objectives: On completion of this article, the reader should be able to determine risks profiles for venous thromboembolism and pulmonary embolism in patients undergoing colon and rectal surgery, and to discuss the benefits of mechanical and pharmacologic venous thromboembolism prophylaxis.

Venous thromboembolism (VTE) is common after major general surgery. The risk of VTE is estimated to be $20 \%$ for general surgical patients and 30\% for patients undergoing colorectal procedures. ${ }^{1}$ Pulmonary embolism (PE) is recognized as the most common cause of preventable hospital deaths, accounting for up to 200,000 deaths annually in the United States. $^{2-9}$ Prevention of postoperative VTE is considered a quality and patient-safety measure in most mandated quality-improvement initiatives. The Centers for Medicare and Medicaid Services (CMS) considers VTE in hospitalized patients a "never event," which is pegged to the "pay for performance" initiative. ${ }^{10,11}$ The majority of patients who develop perioperative VTE are asymptomatic; thus, it is difficult to assess the actual incidence. Studies utilizing venography and fibrinogen uptake test have shown the incidence of deep venous thrombosis (DVT) to be up to $25 \%$. The incidence is even higher in patients with malignancy. ${ }^{12,13}$ Using the NSQIP database, Fleming et al showed that the postdischarge clinical incidence of DVT was 0.47 and $0.26 \%$ for PE among 52, 555 colorectal surgery patients. ${ }^{14}$ The incidence of DVT in patients undergoing colorectal procedures is decreased by $67 \%$ with the use of perioperative prophylaxis. ${ }^{15,16}$ Despite this, studies assessing the practice of surgeons have found that $50 \%$ of general surgery patients received incorrect VTE prophylaxis and half of these did not receive any prophylaxis at all. ${ }^{17}$

\section{Interventions}

Various interventions have been utilized for prophylaxis of venous thromboembolism. These include mechanical devices such as graduated compression stockings (GCS), intermittent pneumatic compression (IPC) devices, and pharmacologic agents such as unfractionated heparin, low-molecular-weight heparin, and fondaparinux. Most of the strategies employ a combination of mechanical methods and pharmacologic agents.

\section{Mechanical Devices}

\section{Graduated Compression Stockings}

The exact mechanism of action of GCS is not well understood. They are believed to work by compressing both the superficial
Issue Theme Perioperative Management; Guest Editor, Sharon L. Stein, MD, FACS
Copyright (c) 2013 by Thieme Medical Publishers, Inc., 333 Seventh Avenue, New York, NY 10001, USA. Tel: +1(212) 584-4662.
DOI http://dx.doi.org/ 10.1055/s-0033-1351130. ISSN 1531-0043. 
and deep venous systems, thereby increasing velocity of venous flow and also helping to empty the cusps of venous valves. ${ }^{18,19}$ They are also believed to increase the plasma levels of tissue factor pathway inhibitor, which is a factor $\mathrm{X}_{\mathrm{a}-}$ dependent inhibitor of the extrinsic pathway of the coagulation cascade. ${ }^{20}$ There are two types of GCS: knee-high and thigh high.

The effectiveness of GCS in the prevention of thromboembolism has been studied extensively in the literature. A systematic review including 15 randomized control trials (RCTs) showed a $64 \%$ relative risk (RR) reduction in general surgical patients. ${ }^{21}$ This reduction was further enhanced by combining with pharmacologic agents. In this review, there were no differences when comparing knee-high versus thighhigh GCS. In a randomized, prospective, controlled trial of 200 patients undergoing abdominal surgery, there was a $57 \%$ reduction in the incidence of deep vein thrombosis diagnosed by ${ }^{125}$ I-fibrinogen test $(p<0.025) .{ }^{22}$ In this study, the effectiveness of GCS was seen in patients with both benign and malignant disease. In another study of GCS in 70 patients undergoing major abdominal surgery, using GCS on one leg and using the other leg as control, DVT was diagnosed by the ${ }^{125}$ I-fibrinogen test. There were 7 bilateral DVTs, 19 unilateral DVTs in the control leg, and only 1 DVT in the GCS group $(p=0.0003) .{ }^{23}$ There are conflicting results with respect to whether thigh-high GCS are better than knee-high GCS. A Cochrane Review of seven RCTs including 1,027 patients, $15 \%$ of patients using GCS developed DVT compared with 29\% in the control group ( $p<0.00001)$. The rate of DVT decreased to $3 \%$ when GCS was combined with another method of prophylaxis compared with $14 \%$ in the control group. ${ }^{24}$

\section{Intermittent Pneumatic Compression Devices}

The mechanism of action of IPC devices has been studied. The sequential application of external compression on the lower extremity is believed to increase pulsatile venous flow. This leads to improved emptying of the veins thereby decreasing venous pressure resulting in an increase in arteriovenous pressure gradient and subsequent increase in arterial flow. ${ }^{25}$ The mechanical forces applied by the IPC devices lead to shear and strain forces on the endothelial cells. This leads to enhanced antithrombotic, profibrinolytic, and vasodilatory effects, including the release of tissue plasminogen activator (tPA). ${ }^{26}$ The increase in tPA is believed to result from a decrease in tissue plasminogen activator inhibitor 1 (tPAI-1). ${ }^{27}$

There are different types of IPCs. The graduated sequential compression devices produce sequential compression from distal to proximal, thereby creating a "milking" effect. ${ }^{28}$ The uniform compression devices produce uniform compression. Both of these are equally effective in reducing the risk of DVTs. ${ }^{29,30}$ A meta-analysis of IPC and DVT prevention in postoperative patients evaluated 15 studies including 2,270 patients. The use of IPC decreased the risk of DVT by $60 \%$ when compared with no prophylaxis $(R R=0.40,95 \%$ confidence interval [CI], 0.29-0.56; $p<0.001) .{ }^{31}$ Most of the studies have showed that a combination of IPCs with pharmacologic methods is more effective than either method alone. A Cochrane Review of 11 studies including over 7,000 patients compared mechanical compression with combination of mechanical methods and pharmacologic methods. ${ }^{32}$ The combined modality was better than mechanical methods alone in decreasing DVT 1 versus $4 \%$ (odds ratio $[\mathrm{OR}]=0.43 ; 95 \% \mathrm{CI}$, 0.24-0.76) and symptomatic pulmonary embolism (PE), 1 versus $3 \%$ ( $O R=0.39 ; 95 \% C I, 0.25-0.63)$. Similarly, the combined modality was better than pharmacologic methods alone in decreasing DVT (0.65 vs. $4.21 \%$; OR $=0.16 ; 95 \% \mathrm{CI}$, 0.07-0.34). Another Cochrane Review specifically looked at thromboprophylaxis in colorectal surgery patients. ${ }^{33}$ This also showed that the combination of mechanical methods with low-dose heparin was better than heparin alone in preventing DVT and/ or PE (OR $=4.17$; 95\% CI, 1.37-12.70).

\section{Pharmacologic Methods}

Low-dose unfractionated heparin (LDUH) and low-molecular-weight heparins (LMWHs) are the main agents used for pharmacologic prophylaxis. Heparin is usually given subcutaneously as 5,000 units every 8 hours or every 12 hours. Lowmolecular-weight heparins inactivate factor $\mathrm{X}_{\mathrm{a}}$, but they have little effect on thrombin due to their structure. ${ }^{34}$ In the United States, LMWHs approved by the U.S. Food and Drug Administration (FDA) include enoxaparin, dalteparin, and tinzaparin. The LMWHs have different structures and pharmacologic properties; therefore, they are not interchangeable with each other or with heparin. ${ }^{35,36}$ Fondaparinux is a synthetic pentasaccharide that binds to antithrombin, but has no effect on thrombin. It does not interact with platelets or platelet factor IV; therefore, it does not cause heparin-induced thrombocytopenia. The particular choice of pharmacologic agent often depends on pricing and hospital preferences.

Using data from the Surgical Care and Outcomes Assessment Program Collaborative Initiative of Washington State, Kwon et al evaluated the 90-day rates of death, clinically relevant VTE, and composite adverse events (CAE) in 4,195 patients. $^{37}$ There were fewer deaths ( 2.5 vs. $1.6 \% ; p=0.03$ ), incidences of VTE (1.8 vs. $1.1 \% ; p=0.04$ ), and CAE ( 4.2 vs. $2.5 \%$; $p=0.002)$ in those who received pharmacologic prophylaxis.

A large multicenter study of 28 centers and over 4,000 patients evaluated the use of LDUH in preventing fatal PE. ${ }^{38} \mathrm{In}$ this study, patients who received LDUH had significantly fewer incidences of asymptomatic DVT, symptomatic DVT/ $\mathrm{PE}$, and fatal PE when compared with controls (0.1 vs. $0.7 \%$ ). One of the centers had inconsistent data; hence, the above study was reappraised to exclude data from that center. The results did not significantly differ. ${ }^{39}$

Multiple studies have shown that both LDUH and LMWH are equally effective in preventing DVT and PE. ${ }^{40-43}$ A metaanalysis of LMWH versus no prophylaxis or placebo showed that LMWH decreased the risk of DVT by $72 \%, \mathrm{RR}=0.28(95 \%$ CI, $0.14-0.54 ; p<0.001$ ) and clinical PE by $75 \%, \mathrm{RR}=0.25$ (95\% CI, 0.08-0.79; $p=0.018$ ) and $71 \%$ for clinical VTE, $\mathrm{RR}=0.29$ (95\% CI, 0.11-0.73; $p=0.009$ ). There was no significant decrease in risk of mortality; however, there was a significant increase in bleeding complications. ${ }^{44}$ The LMWH used in these studies included enoxaparin, dalteparin, nadroparin, tinzaparin, and Parnaparin. 
Fondaparinux was compared with dalteparin in a RCT, which was designed as a noninferiority study. ${ }^{45}$ Fondaparinux was associated with a $24.6 \% \mathrm{RR}$ reduction in all patients, but this was not statistically significant (95\% CI, -9.0-47.9; $p=0.144$ ) A post hoc analysis suggested improved efficacy (RR: 40\%) in reducing VTE for fondaparinux in a large subgroup of patients with malignancy. There was no significant difference in major bleeding rates.

\section{Risk Category}

The intensity of VTE prophylaxis for colorectal surgery patients should be commensurate with the estimated risk. The type of procedure and VTE risk factors determine the overall risk category. There are several published guidelines that differ substantially in the methods used to assess risk of VTE. These differences exist secondary to factors such as bias, cost, safety, efficacy, and ease of implementation. For greater than 20 years, the American College of Chest Physi- cians (ACCP) has published extensive evidenced-based guidelines on the use of antithrombotic therapy. ${ }^{46}$ The latest update utilizes a risk stratification model based on two previously validated risk factor point systems Rogers Score (-Table 1) and Caprini Score (-Table 2). ${ }^{47-49}$ Furthermore, the Society of American Gastrointestinal and Endoscopic Surgeons (SAGES), the American Society of Clinical Oncology (ASCO), and the National Comprehensive Cancer Network (NCCN) have each developed risk assessment guidelines for laparoscopic surgery and cancer patients, respectively. The following section outlines the evidence for risk stratification. A summary table is provided (-Table $\mathbf{3}$ ) to help categorize colorectal patients in adherence to the latest ACCP and ASCO recommendations.

The risk of VTE in colorectal surgery patients varies depending on both patient-specific and procedure-specific factors. VTE risk appears to be highest for patients undergoing abdominal or pelvic surgery for cancer and lowest for young patients undergoing ambulatory procedures. ${ }^{50-53}$ Patient-

Table 1 Risk assessment model from the patient safety in surgery study: Rogers Score

\begin{tabular}{|c|c|c|}
\hline General risk factor & Specific risk factor & Risk score points \\
\hline \multirow[t]{7}{*}{ Operation type } & Respiratory & 9 \\
\hline & Thoracoabdominal aneurysm & 7 \\
\hline & Abdominal aneurysm & 4 \\
\hline & Mouth, palate & 4 \\
\hline & Stomach, small/large intestine & 4 \\
\hline & Integument & 3 \\
\hline & Hernia & 2 \\
\hline \multirow[t]{2}{*}{ ASA } & $3,4,5$ & 2 \\
\hline & 2 & 1 \\
\hline \multicolumn{3}{|l|}{ Female sex } \\
\hline \multirow[t]{2}{*}{ Work RVU } & $>17$ & 3 \\
\hline & $10-17$ & 2 \\
\hline \multirow[t]{5}{*}{2 point conditions } & Disseminated cancer & 2 \\
\hline & Chemotherapy within $30 \mathrm{~d}$ & 2 \\
\hline & Preoperative serum sodium $>145 \mathrm{mmol} / \mathrm{L}$ & 2 \\
\hline & Transfusion $>4$ units packed RBCs in 72 h within operation & 2 \\
\hline & Ventilator dependent & 2 \\
\hline \multirow[t]{6}{*}{ One point conditions } & Wound class 3 or 4 & 1 \\
\hline & Preoperative Hct $<38$ & 1 \\
\hline & Preoperative bili $>1.0$ & 1 \\
\hline & Dyspnea & 1 \\
\hline & Albumin $<3.5$ & 1 \\
\hline & Emergency & 1 \\
\hline \multirow[t]{3}{*}{ Zero point conditions } & ASA class 1 & 0 \\
\hline & Work RVU $<10$ & 0 \\
\hline & Male sex & 0 \\
\hline
\end{tabular}

Abbreviations: ASA, American Society of Anesthesiologists; Hct, hematocrit; RBCs, red blood cells; RVU, relative value update. 
Table 2 Caprini risk assessment model

\begin{tabular}{|c|c|c|c|}
\hline One point & Two points & Three points & Five points \\
\hline Age $41-60$ y & Age $61-74$ y & Age $>75 y$ & Stroke $(<1 \mathrm{mo})$ \\
\hline Minor surgery & Arthroscopic surgery & History of VTE & Elective arthroplasty \\
\hline $\mathrm{BMI}>25 \mathrm{~kg} / \mathrm{m}^{2}$ & Major open surgery (> 45 min) & Factor V Leiden & Hip, pelvis, or leg fracture \\
\hline Swollen legs & Laparoscopic surgery (> $45 \mathrm{~min})$ & Lupus anticoagulant & $\begin{array}{l}\text { Acute spinal cord injury } \\
(<1 \mathrm{mo})\end{array}$ \\
\hline Varicose veins & Malignancy & Anticardiolipin antibodies & \\
\hline Pregnancy or postpartum & Confined to bed (> 72 hour) & $\begin{array}{l}\text { Elevated serum } \\
\text { homocysteine }\end{array}$ & \\
\hline History of spontaneous abortion & Immobilizing cast & $\begin{array}{l}\text { Heparin-induced } \\
\text { thrombocytopenia }\end{array}$ & \\
\hline Oral contraceptives & Central venous access & $\begin{array}{l}\text { Other congenital or } \\
\text { acquired thrombophilia }\end{array}$ & \\
\hline \multicolumn{4}{|l|}{ Sepsis $(<1$ mo $)$} \\
\hline \multicolumn{4}{|l|}{ COPD, pneumonia $(<1 \mathrm{mo})$} \\
\hline \multicolumn{4}{|l|}{ Abnormal PFTs } \\
\hline \multicolumn{4}{|l|}{ Acute myocardial infarction } \\
\hline \multicolumn{4}{|l|}{ Congestive heart failure } \\
\hline \multicolumn{4}{|l|}{ inflammatory bowel disease } \\
\hline Bed rest & & & \\
\hline
\end{tabular}

Abbreviations: BMI, body mass index; COPD, chronic obstructive pulmonary disease; PFTs, pulmonary function tests; VTE, venous thromboembolism.

Table 3 Risk stratification for VTE in general gastrointestinal and abdominal-pelvic surgery

\begin{tabular}{|l|l|l|l|l|}
\hline Risk category & Rogers Score & Caprini Score & Observed risk of VTE (\%) & $\begin{array}{l}\text { Estimated baseline risk } \\
\text { without prophylaxis (\%) }\end{array}$ \\
\hline Very low & $<7$ & 0 & 0 & $<0.5$ \\
\hline Low & $7-10$ & $1-2$ & 0.7 & 1.5 \\
\hline Moderate & $>10$ & $3-4$ & 1.0 & 3.0 \\
\hline High & NA & 5 or $>5$ & 1.9 & 6.0 \\
\hline
\end{tabular}

Abbreviations: NA, not applicable; VTE, venous thromboembolism.

specific factors have been analyzed in three relatively large studies of VTE in mixed surgical populations. Independent risk factors in these studies include age $>60$ years, prior VTE, and cancer $^{54}$; age $>60$ years, prior VTE, anesthesia $>2$ hours, and bed rest $>4$ days $^{52}$; older age, male sex, longer length of hospital stay, and higher Charlson Comorbidity Score ${ }^{55}$; and sepsis, pregnancy, or postpartum state; central venous access; malignancy; prior VTE; and inpatient hospital stay $>2$ days. $^{56}$

In another study looking at the risk related to postoperative complications, the moderate to strong independent risk factors for VTE included urinary tract infection, acute renal insufficiency, postoperative transfusion, perioperative myocardial infarction, and pneumonia. ${ }^{57}$ Cancer patients who are scheduled to undergo colorectal surgery are a special group with a particularly high risk for VTE. Even with prophylaxis, cancer patients have a twofold higher risk for postoperative VTE compared with noncancer patients ${ }^{58}$; if VTE occurs, they have a threefold risk for fatal PE. ${ }^{59}$
Several practical and evidence-based models or guidelines exist for risk stratification. Each has limitations, but two specific models were rigorously developed, validated, and recently incorporated into the ACCP recommendations. These risk assessment scales are currently utilized by numerous academic and community hospitals in an effort to standardize evidence-based criteria for VTE prophylaxis.

The first model used data from 183,069 patients in the Patient Safety in Surgery Study. This study included patients who underwent general, vascular, and thoracic procedures at one of 128 Veterans Administration medical centers or 14 private-sector hospitals between 2002 and 2004. ${ }^{47}$ Points were calculated for variables that were found to be independent predictors of VTE risk. The total number of points in this trial is named the Rogers Score. These variables include type of operation, work relative value units, several patient characteristics, and specific laboratory values ( - Table $\mathbf{1}$ ). The risk of symptomatic VTE varied from very low $(0.1 \%)$ to low $(0.5 \%)$ to moderate (1.5\%) in both development and validation studies. 
This model was unique at the time of publication, but has limitations. The categories included can be cumbersome when a quick calculation is needed and the actual number of patients that received treatment during the developmental study is nebulous. Therefore, this system has largely been used to substantiate and supplement other risk-stratification models.

The second model included in the ACCP 2012 guidelines ${ }^{46}$ also estimates VTE risk by adding points for various VTE risk factors (- Table 2). ${ }^{48,49}$ VTE risk is categorized as being very low (0-1 point), low ( 2 points), moderate ( $3-4$ points), or high ( $\geq 5$ points). In contrast to the Rogers Score, this model (the Caprini Score) is relatively easy to use and appears to discriminate reasonably well among patients at low, moderate, and high risk for VTE. Furthermore, the Caprini Score was validated in a large retrospective study in a sample of general, vascular, and urologic surgery patients. ${ }^{56}$ This study included a representative sample of surgical patients, avoided exclusions, minimized losses to follow-up, and had a low risk of bias. The authors also collected information about prophylaxis received. This allowed the ACCP investigators to adjust for this variable and estimate what the baseline risk of VTE would have been in the absence of prophylaxis. Although neither the Caprini Score nor the Rogers Score has yet been validated specifically in colorectal surgery, patients are similar to the abdominal and pelvic surgery patients in this trial.

The ACCP investigators also derived estimates of the baseline risk of VTE. They used the observed risks of VTE reported in the validation study by Bahlet $\mathrm{al}^{57}$ and adjusted for prophylaxis received. The estimated baseline risks of VTE were $0.5,1.5,3.0$ and $6.0 \%$ in patients at very low, low, moderate, and high risk for VTE, respectively (-Table 3).

\section{Recommendations}

Patients undergoing minor colorectal surgery without additional VTE risk factors, who have a Rogers Score less than 7 and Caprini Score of 0, are considered very low risk. Early and frequent ambulation is recommended in these patients without mechanical or pharmacologic prophylaxis. ${ }^{46}$ An example would include a patient under the age of 40 undergoing a lateral internal sphincterotomy.

Patients considered low risk (Rogers Score =7-10; Caprini Score $=1-2$ ) benefit from mechanical prophylaxis with intermittent pneumatic compression over no prophylaxis. ${ }^{46}$ For colorectal procedures, low risk includes noncancer patients over the age of 40 , undergoing anorectal surgery with one or fewer additional risk factors.

For moderate risk colorectal patients (Rogers Score $>10$, Caprini Score $=3-4$ ) the recommended approaches include pharmacologic (LDUH twice daily, LMWH, or fondaparinux) or mechanical prophylaxis with IPC. Patients not at high risk for bleeding with moderate risk for VTE should receive one of the pharmacologic agents above, while those at high risk of bleeding should use IPC. ${ }^{46}$ Accepted risk factors for bleeding include bleeding disorders, concomitant use of clopidogrel or aspirin, renal dysfunction, conditions in which bleeding would be catastrophic, high-risk uncontrolled hemorrhage, thrombocyto- penia, and liver disease with coagulopathy. ${ }^{60}$ Furthermore, patients categorized as moderate risk preoperatively may fall into a higher risk category after surgery if intraoperative findings or postoperative complications change the overall score.

High-risk patients (Caprini Score $\geq 5$ ), not at high risk for bleeding, should receive both pharmacologic and mechanical prophylaxis. The choice of agent (-Table 3 ) is typically dependent on the institution, current pathway, cost, and availability. Colorectal cancer patients are considered very high risk and thromboprophylaxis (LDUH 3 times daily, LMWH, or fondaparinux $)^{61}$ should be combined with mechanical prophylaxis. Fondaparinux (Arixtra; GlaxoSmithKline, London, UK) should be considered in colorectal cancer patients without increased bleeding risk. As outlined above, the RCT of fondaparinux versus LMWH found a significant risk reduction in VTE among patients with abdominal and pelvic cancer. $^{45}$ In addition, it is recommended that colorectal cancer patients with residual malignant disease after surgery, obese patients, or patients with histories of VTE receive extended prophylaxis (up to 4 weeks) with LMWH. ${ }^{61}$

\section{References}

1 McLeod RS, Geerts WH, Sniderman KW, et al; Canadian Colorectal Surgery DVT Prophylaxis Trial investigators. Subcutaneous heparin versus low-molecular-weight heparin as thromboprophylaxis in patients undergoing colorectal surgery: results of the canadian colorectal DVT prophylaxis trial: a randomized, double-blind trial. Ann Surg 2001;233(3):438-444

2 Horlander KT, Mannino DM, Leeper KV. Pulmonary embolism mortality in the United States, 1979-1998: an analysis using multiple-cause mortality data. Arch Intern Med 2003;163(14): 1711-1717

3 Lindblad B, Eriksson A, Bergqvist D. Autopsy-verified pulmonary embolism in a surgical department: analysis of the period from 1951 to 1988 . Br J Surg 1991;78(7):849-852

4 Stein PD, Henry JW. Prevalence of acute pulmonary embolism among patients in a general hospital and at autopsy. Chest 1995; 108(4):978-981

5 White RH, Zhou H, Romano PS. Incidence of symptomatic venous thromboembolism after different elective or urgent surgical procedures. Thromb Haemost 2003;90(3):446-455

6 Sandler DA, Martin JF. Autopsy proven pulmonary embolism in hospital patients: are we detecting enough deep vein thrombosis? J R Soc Med 1989;82(4):203-205

7 Martino MA, Borges E, Williamson E, et al. Pulmonary embolism after major abdominal surgery in gynecologic oncology. Obstet Gynecol 2006;107(3):666-671

8 Dalen JE, Alpert JS. Natural history of pulmonary embolism. Prog Cardiovasc Dis 1975;17(4):259-270

9 Dismuke SE, Wagner EH. Pulmonary embolism as a cause of death. The changing mortality in hospitalized patients. JAMA 1986;255 (15):2039-2042

10 Sutedjo JL, Ng RK, Piazza G, Goldhaber SZ. Medicare's new regulations for deep vein thrombosis as a "never event": wise or worrisome? Am J Med 2009;122(11):975-976

11 Passman MA. Mandated quality measures and economic implications of venous thromboembolism prevention and management. Am J Surg 2010;199(1, Suppl):S21-S31

12 Khorana AA, Francis CW, Culakova E, Kuderer NM, Lyman GH. Thromboembolism is a leading cause of death in cancer patients receiving outpatient chemotherapy. J Thromb Haemost 2007;5 (3):632-634 
13 Heit JA, Silverstein MD, Mohr DN, Petterson TM, O’Fallon WM, Melton LJ III. Risk factors for deep vein thrombosis and pulmonary embolism: a population-based case-control study. Arch Intern Med 2000;160(6):809-815

14 Fleming FJ, Kim MJ, Salloum RM, Young KC, Monson JR. How much do we need to worry about venous thromboembolism after hospital discharge? A study of colorectal surgery patients using the National Surgical Quality Improvement Program database. Dis Colon Rectum 2010;53(10):1355-1360

15 Geerts WH, Heit JA, Clagett GP, et al. Prevention of venous thromboembolism. Chest 2001;119(1, Suppl):132S-175S

16 Huber O, Bounameaux H, Borst F, Rohner A. Postoperative pulmonary embolism after hospital discharge. An underestimated risk. Arch Surg 1992;127(3):310-313

17 Stratton MA, Anderson FA, Bussey HI, et al. Prevention of venous thromboembolism: adherence to the 1995 American College of Chest Physicians consensus guidelines for surgical patients. Arch Intern Med 2000;160(3):334-340

18 Litter J. Thromboembolism; its prophylaxis and medical treatment; recent advances. Med Clin North Am 1952;36(5):1309-1321

19 Lewis CE Jr, Antoine J, Mueller C, Talbot WA, Swaroop R, Edwards WS. Elastic compression in the prevention of venous stasis. A critical reevaluation. Am J Surg 1976;132(6):739-743

20 Arcelus JI, Caprini JA, Hoffman KN, Traverso CI, Hoppensteadt D, Fareed J. Modifications of plasma levels of tissue factor pathway inhibitor and endothelin- 1 induced by a reverse Trendelenburg position: influence of elastic compression-preliminary results. J Vasc Surg 1995;22(5):568-572

21 Agu O, Hamilton G, Baker D. Graduated compression stockings in the prevention of venous thromboembolism. Br J Surg 1999;86 (8):992-1004

22 Allan A, Williams JT, Bolton JP, Le Quesne LP. The use of graduated compression stockings in the prevention of postoperative deep vein thrombosis. Br J Surg 1983;70(3):172-174

23 Kakkos SK, Daskalopoulou SS, Daskalopoulos ME, Nicolaides AN, Geroulakos G. Review on the value of graduated elastic compression stockings after deep vein thrombosis. Thromb Haemost 2006;96(4):441-445

24 Amaragiri SV, Lees TA. Elastic compression stockings for prevention of deep vein thrombosis. Cochrane Database Syst Rev 2000; (3):CD001484

25 Allwood MJ. The effect of an increased local pressure gradient on blood flow in the foot. Clin Sci (Lond) 1957;16(2):231-239

26 Chen AH, Frangos SG, Kilaru S, Sumpio BE. Intermittent pneumatic compression devices-physiological mechanisms of action. Eur J Vasc Endovasc Surg 2001;21(5):383-392

27 Comerota AJ, Chouhan V, Harada RN, et al. The fibrinolytic effects of intermittent pneumatic compression: mechanism of enhanced fibrinolysis. Ann Surg 1997;226(3):306-313, discussion 313-314

28 Morris RJ, Woodcock JP. Evidence-based compression: prevention of stasis and deep vein thrombosis. Ann Surg 2004;239(2):162-171

29 Salzman EW, McManama GP, Shapiro AH, et al. Effect of optimization of hemodynamics on fibrinolytic activity and antithrombotic efficacy of external pneumatic calf compression. Ann Surg 1987;206(5):636-641

30 Proctor MC, Greenfield LJ, Wakefield TW, Zajkowski PJ. A clinical comparison of pneumatic compression devices: the basis for selection. J Vasc Surg 2001;34(3):459-463, discussion 463-464

31 Urbankova J, Quiroz R, Kucher N, Goldhaber SZ. Intermittent pneumatic compression and deep vein thrombosis prevention. A meta-analysis in postoperative patients. Thromb Haemost 2005;94 (6):1181-1185

32 Kakkos SK, Caprini JA, Geroulakos G, Nicolaides AN, Stansby GP, Reddy DJ. Combined intermittent pneumatic leg compression and pharmacological prophylaxis for prevention of venous thromboembolism in high-risk patients. Cochrane Database Syst Rev 2008; (4):CD005258
33 Wille-Jørgensen P, Rasmussen MS, Andersen BR, Borly L. Heparins and mechanical methods for thromboprophylaxis in colorectal surgery. Cochrane Database Syst Rev 2004;(1):CD001217

34 Weitz JI. Low-molecular-weight heparins. N Engl J Med 1997;337 (10):688-698

35 White RH, Ginsberg JS. Low-molecular-weight heparins: are they all the same? Br J Haematol 2003;121(1):12-20

36 Nightingale SL. From the Food and Drug Administration. JAMA 1993;270(14):1672

37 Kwon S, Meissner M, Symons R, et al; Surgical Care and Outcomes Assessment Program Collaborative. Perioperative pharmacologic prophylaxis for venous thromboembolism in colorectal surgery. J Am Coll Surg 2011;213(5):596-603, e1

38 International Multicentre Trial. Prevention of fatal postoperative pulmonary embolism by low doses of heparin. An international multicentre trial. Lancet 1975;2(7924):45-51

39 Kakkar VV, Corrigan TP, Fossard DP, Sutherland I, Thirwell J. Prevention of fatal postoperative pulmonary embolism by low doses of heparin. Reappraisal of results of international multicentre trial. Lancet 1977;1(8011):567-569

40 McLeod RS, Geerts WH, Sniderman KW, et al; Canadian Colorectal Surgery DVT Prophylaxis Trial investigators. Subcutaneous heparin versus low-molecular-weight heparin as thromboprophylaxis in patients undergoing colorectal surgery: results of the Canadian colorectal DVT prophylaxis trial: a randomized, double-blind trial. Ann Surg 2001;233(3):438-444

41 Bergqvist D, et al; ENOXACAN Study Group. Efficacy and safety of enoxaparin versus unfractionated heparin for prevention of deep vein thrombosis in elective cancer surgery: a double-blind randomized multicentre trial with venographic assessment. Br J Surg 1997;84(8):1099-1103

42 Etchells E, McLeod RS, Geerts W, Barton P, Detsky AS. Economic analysis of low-dose heparin vs the low-molecular-weight heparin enoxaparin for prevention of venous thromboembolism after colorectal surgery. Arch Intern Med 1999;159(11): 1221-1228

43 National Collaborating Centre for Acute Care. Venous thromboembolism: reducing the risk of venous thromboembolism (deep vein thrombosis and pulmonary embolism) in patients admitted to hospital. London, England: NICE; 2010

44 Mismetti P, Laporte S, Darmon JY, Buchmüller A, Decousus H. Meta-analysis of low molecular weight heparin in the prevention of venous thromboembolism in general surgery. Br J Surg 2001;88 (7):913-930

45 Agnelli G, Bergqvist D, Cohen A, Gallus A, Gent M; PEGASUS investigators. Randomized clinical trial of postoperative fondaparinux versus perioperative dalteparin for prevention of venous thromboembolism in high-risk abdominal surgery. J Surg 2005;92 (10):1212-1220

46 American College of Chest Physicians. Prevention of VTE in nonorthopedic surgical patients antithrombotic therapy and prevention of thrombosis. ACCP Guidelines. 9th ed. Northbrook, IL: American College of Chest Physicians; 2012:s240-242

47 Rogers SO Jr, Kilaru RK, Hosokawa P, Henderson WG, Zinner MJ Khuri SF. Multivariable predictors of postoperative venous thromboembolic events after general and vascular surgery: results from the patient safety in surgery study. J Am Coll Surg 2007;204 (6):1211-1221

48 Caprini JA. Thrombosis risk assessment as a guide to quality patient care. Dis Mon 2005;51(2-3):70-78

49 Caprini JA, Arcelus JI, Hasty JH, Tamhane AC, Fabrega F. Clinical assessment of venous thromboembolic risk in surgical patients. Semin Thromb Hemost 1991;17(Suppl 3):304-312

50 Catheline JM, Capelluto E, Gaillard JL, Turner R, Champault G. Thromboembolism prophylaxis and incidence of thromboembolic complications after laparoscopic surgery. Int J Surg Investig 2000;2 (1):41-47 
51 White $\mathrm{RH}$, Zhou H, Romano PS. Incidence of symptomatic venous thromboembolism after different elective or urgent surgical procedures. Thromb Haemost 2003;90(3):446-455

52 Agnelli G, Bolis G, Capussotti L, et al. A clinical outcome-based prospective study on venous thromboembolism after cancer surgery: the @RISTOS project. Ann Surg 2006;243(1):89-95

53 Alcalay A, Wun T, Khatri V, et al. Venous thromboembolism in patients with colorectal cancer: incidence and effect on survival. J Clin Oncol 2006;24(7):1112-1118

54 Clarke-Pearson DL, Dodge RK, Synan I, McClelland RC, Maxwell GL. Venous thromboembolism prophylaxis: patients at high risk to fail intermittent pneumatic compression. Obstet Gynecol 2003;101 (1):157-163

55 Spyropoulos AC, Hussein M, Lin J, Battleman D. Rates of venous thromboembolism occurrence in medical patients among the insured population. Thromb Haemost 2009;102(5):951-957

56 Bahl V, Hu HM, Henke PK, Wakefield TW, Campbell DA Jr, Caprini JA. A validation study of a retrospective venous thromboembolism risk scoring method. Ann Surg 2010;251(2):344-350
57 Gangireddy C, Rectenwald JR, Upchurch GR, et al. Risk factors and clinical impact of postoperative symptomatic venous thromboembolism. J Vasc Surg 2007;45(2):335-341, discussion 341-342

58 Falanga A, Zacharski L. Deep vein thrombosis in cancer: the scale of the problem and approaches to management. Ann Oncol 2005;16 (5):696-701

59 Kakkar AK, Levine M, Pinedo HM, Wolff R, Wong J. Venous thrombosis in cancer patients: insights from the FRONTLINE survey. Oncologist 2003;8(4):381-388

60 Lowinger JS, Maxwell DJ. Heparins for venous thromboembolism prophylaxis-safety issues. Aust Prescr 2009;32: $108-112$

61 Lyman GH, Khorana AA, Falanga A, et al; American Society of Clinical Oncology. American Society of Clinical Oncology guideline: recommendations for venous thromboembolism prophylaxis and treatment in patients with cancer. J Clin Oncol 2007;25 (34):5490-5505 